\title{
Therapeutic Action of Cannabinoids in a Murine Model of Multiple Sclerosis
}

\author{
Ángel Arévalo-Martín, ${ }^{1}$ José Miguel Vela, ${ }^{2}$ Eduardo Molina-Holgado, ${ }^{1}$ José Borrell, ${ }^{1}$ and Carmen Guaza ${ }^{1}$ \\ ${ }^{1}$ Neuroimmunology Group, Neural Plasticity Department, Cajal Institute, Consejo Superior de Investigaciones Científicas, 28002 Madrid, Spain, and ${ }^{2}$ Unit \\ of Histology, School of Medicine, Department of Cell Biology, Physiology, and Immunology, Universidad Autonoma de Barcelona, 08193 Bellaterra, \\ Barcelona, Spain
}

Theiler's virus infection of the CNS induces an immune-mediated demyelinating disease in susceptible mouse strains and serves as a relevant infection model for human multiple sclerosis (MS). Cannabinoids may act as immunosuppressive compounds that have shown therapeutic potential in chronic inflammatory disorders. Using the Theiler's murine encephalomyelitis virus model, we report here that treatment with the synthetic cannabinoids WIN 55,212-2, ACEA, and JWH-015 during established disease significantly improved the neurological deficits in a long-lasting way. At a histological level, cannabinoids reduced microglial activation, abrogated major histocompatibility complex class II antigen expression, and decreased the number of CD4+ infiltrating T cells in the spinal cord. Both recovery of motor function and diminution of inflammation paralleled extensive remyelination. Overall, the data presented may have potential therapeutic implications in demyelinating pathologies such as MS; in particular, the possible involvement of cannabinoid receptor CB2 would enable nonpsychoactive therapy suitable for long-term use.

Key words: Theiler's virus; CB1 agonists; CB2 agonists; demyelination; neuroinflammation; remyelination; spinal cord; rotarod

\section{Introduction}

Multiple sclerosis (MS) is the most common chronic inflammatory, demyelinating disease of the CNS in humans and is characterized by neurological deficits including sensory deficits, motor weakness, tremor, and ataxia. Demyelination is considered to occur as a consequence of a chronic inflammation in which circulating $\mathrm{T}$ cells and macrophages infiltrated into the CNS get involved in the development of the demyelinated plaques that characterize the disease (Noseworthy et al., 2000). The mechanisms of the immune-mediated injury of myelin sheaths are thought to involve an indirect bystander injury and an autoimmune response against myelin epitopes. The etiology of MS is still unknown, but epidemiological studies suggest a role for viruses in triggering the disease (Johnson, 1994). Several viruses have been shown to induce CNS demyelination in animals, and Theiler's virus provides the best studied model. Theiler's murine encephalomyelitis virus (TMEV) is a picornavirus natural pathogen in mice that, when injected intracerebrally in susceptible strains, induces a chronic, progressive, demyelinating disease that resembles progressive MS (Dal Canto and Lipton, 1977). An immune response directed against viral and myelin epitopes takes place in the CNS of TMEV-infected mice (Miller et al., 1997), and this event is considered to be the cause of the TMEV-induced

Received Nov. 1, 2002; revised Dec. 23, 2002; accepted Dec. 27, 2002.

This work was supported by grants from the Ministerio de Ciencia y Tecnología (Spain, SAF-2001/1246). We gratefully appreciate Dr. R. P. Roos (University of Chicago) for delivery of Theiler's virus. We express our gratitude to E. Baides, C. Bailón, and C. Hernández for their excellent technical assistance.

Correspondence should be addressed to Carmen Guaza, Cajal Institute, Consejo Superior de Investigaciones Científicas, Avenida Doctor Arce 37, 28002 Madrid, Spain. E-mail: cgjb@cajal.csic.es.

Copyright $\odot 2003$ Society for Neuroscience $\quad 0270-6474 / 03 / 232511-06 \$ 15.00 / 0$ demyelinating disease (TMEV-IDD). Mice exhibit several clinical deficits, including progressive impaired motor coordination, incontinence, and paralysis associated with axonal loss and electrophysiological abnormalities (McGavern et al., 2000).

Cannabinoids, the bioactive components of Cannabis sativa, are immunosuppressors by affecting cell function ( $\mathrm{Zhu}$ et al., 1998; Mc Coy et al., 1999) and by inhibiting proinflammatory soluble mediators (Klein et al., 2000). On this basis, cannabidiol, the nonpsychoactive cannabinoid, ameliorated chronic inflammation in a mouse model of rheumatoid arthritis (Malfait et al., 2000). In experimental autoimmune encephalomyelitis (EAE), $\Delta^{9}$-tetrahydrocannabinol (THC), the major psychotropic constituent of marijuana, was effective in delaying the onset of disease when administered before induction (Lyman et al., 1989). Synthetic cannabinoids also reduce spasticity and tremor in mice with chronic relapsing EAE (Baker et al., 2000), accordingly to their actions on pain and motor pathways in the CNS. Limited clinical studies have suggested beneficial effects of cannabinoids (for review, see Pertwee, 2002), and the possible role of the endocannabinoid system in MS symptomatology has also been discussed (Di Marzo et al., 2000).

Cannabinoids are hydrophobic compounds that exert most of their actions via the activation of specific G-protein-coupled receptors. To date, two cannabinoid receptors have been cloned and characterized, cannabinoid type 1 receptor $\left(\mathrm{CB}_{1}\right)$ and cannabinoid type 2 receptor $\left(\mathrm{CB}_{2}\right)$, although additional receptors may exist (Matsuda et al., 1990; Di Marzo et al., 2001). The $\mathrm{CB}_{1}$ receptor is expressed primarily in the CNS (Herkenham et al., 1990) and is responsible for the psychotropic effects of cannabinoids, whereas the $\mathrm{CB}_{2}$ receptor is expressed predominantly in immune 
cells (Bouaboula et al., 1993; Munro et al., 1993). Nevertheless, $\mathrm{CB}_{1}$ receptor expression is also reported in immune cells $(\mathrm{Ga}-$ liegue et al., 1995). Several endogenous lipids have been isolated and characterized as natural ligands for both receptors (Devane et al., 1992; Mechoulam et al., 1995), and an endocannabinoid system is known to operate, but its regulation and functions are not yet well understood (for review, see Piomelli et al., 2000).

Our study reports a therapeutic effect of synthetic cannabinoids on TMEV-IDD. Cannabinoid treatment during established clinical disease restores motor coordination, diminishes inflammation, and promotes remyelination in TMEV-infected mice.

\section{Materials and Methods}

Animals and Theiler's virus inoculation. We used female SJL/J mice, susceptible to TMEV-IDD development, from our in-house colony (Cajal Institute, Madrid, Spain), maintained on food and water ad libitum in a $12 \mathrm{hr}$ light/dark cycle. Four-week-old mice were inoculated intracerebrally in the right cerebral hemisphere with $10^{6}$ pfu of BeAn TMEV strain in $30 \mu \mathrm{l}$ of DMEM supplemented with $10 \%$ of FCS as previously described (Lledó et al., 1999). Handling of animals was performed in compliance with the guidelines of animal care set by the European Union (86/609/EEC).

Evaluation of motor coordination. To evaluate neurological deficits of mice, we used the rotarod test, which measures balance, coordination, and motor control. The rotarod apparatus (Ugo Basile, Comerio, Italy) consists of a suspended rod able to run at constant or at accelerating speed. All mice were exposed to a training period at constant speed to familiarize them with the apparatus before cannabinoid treatment and at accelerating speed while the test was being performed. Data were collected from mouse rotarod performance $1 \mathrm{~d}$ before the beginning of treatment, $1 \mathrm{~d}$ after the end of the treatment, and $25 \mathrm{~d}$ later. The trial was terminated when mice fell from the apparatus or after a maximum of 5 min. We analyzed data with a two-way ANOVA and Student's $t$ test.

Experimental procedure. At $60 \mathrm{~d}$ after TMEV infection, neurological dysfunction was tested by the rotarod assay, and mice were assigned to four groups, with initially no significant differences between them in their ability to perform the rotarod test. Mice from these groups were injected intraperitoneally once a day for $10 \mathrm{~d}$ with WIN 55,212-2 (nonselective $\mathrm{CB}_{1} / \mathrm{CB}_{2}$ agonist), $\mathrm{ACEA}\left(>1400\right.$-fold $\mathrm{CB}_{1}$ selectivity over $\mathrm{CB}_{2}$ ), JWH-015 (23-fold CB2 selectivity over $\mathrm{CB}_{1}$ ), or vehicle. Doses were calculated based on their receptor binding affinities, but this estimate does not take account of pharmacokinetics of the individual compounds (Pertwee, 1999). We evaluated effects of WIN 55,212-2 and ACEA on motor function by testing spontaneous locomotor activity (Activity Monitor System; Omnitech Electronics, Columbus, OH). Naive $\mathrm{SJL} / \mathrm{J}$ mice were injected intraperitoneally either with $5 \mathrm{mg} / \mathrm{kg}$ of WIN $55,212-2,2.5 \mathrm{mg} / \mathrm{kg}$ of ACEA, or the appropriate vehicle and immediately introduced into the activity cage for a $60 \mathrm{~min}$ session. Mice injected with WIN-55,212-2 displayed lower locomotor response than controls, but no typical signs of catalepsy, as frozen postures or immobility were observed (our unpublished results). To avoid potential habituation, cannabinoid agonist doses were increased through time as treatment advanced as follows: $2.5 \mathrm{mg} / \mathrm{kg}$ of WIN 55,212-2 for $3 \mathrm{~d}, 3.75 \mathrm{mg} / \mathrm{kg}$ on days $4-6$, and $5 \mathrm{mg} / \mathrm{kg}$ on days $7-10$. WIN $55,212-2$ doses were based on a previous report (Baker et al., 2000). ACEA doses were $1.25 \mathrm{mg} / \mathrm{kg}$ on days $1-3,1.9 \mathrm{mg} / \mathrm{kg}$ on days $4-6$, and $2.5 \mathrm{mg} / \mathrm{kg}$ on the last $4 \mathrm{~d}$ of treatment. JWH-015 was injected at $0.6 \mathrm{mg} / \mathrm{kg}$ for $3 \mathrm{~d}, 0.9 \mathrm{mg} / \mathrm{kg}$ on days $4-6$, and $1.2 \mathrm{mg} / \mathrm{kg}$ on the last $4 \mathrm{~d}$. Vehicle-injected mice received a solution of $5 \%$ BSA and $0.2 \%$ DMSO in PBS. The number of mice for each treatment was 12; half were killed to process the spinal cord the day after treatment termination, and the remainder were maintained for $25 \mathrm{~d}$ to reach 5 weeks from the beginning of treatment; this period is considered optimal to evaluate remyelination induced by any event (Warrington et al., 2000).

Tissue processing. Mice were anesthetized by intraperitoneal pentobarbital administration and perfused transcardially with $4 \%$ paraformaldehyde in $0.1 \mathrm{M}$ phosphate buffer (PB). Spinal cords were collected and divided into five segments. From each segment, $\sim 1 \mathrm{~mm}$ was postfixed in $2.5 \%$ glutaraldehyde and $2 \%$ paraformaldehyde in $0.1 \mathrm{M} \mathrm{PB}$ for $1 \mathrm{hr}$, stained with $1 \%$ osmium tetraoxide in water for $1 \mathrm{hr}$, and embedded in Araldite epoxy resin (TAAB, Aldermaston, UK). Tissue was then cut with an ultramicrotome to obtain $1 \mu \mathrm{m}$ semithin sections and stained with toluidine blue. The remaining tissue was postfixed in $4 \%$ paraformaldehyde in $0.1 \mathrm{~PB}$, cryoprotected with a $30 \%$ solution of sucrose in $0.1 \mathrm{~PB}$, and frozen in dry ice. We then obtained $35-\mu \mathrm{m}$-thick coronal cryostat sections and processed them to visualize microglia/macrophages using Mac- 1 anti-CD11b antibody (Serotec, Oxford, UK), CD4 ${ }^{+}$T cells (BD PharMingen, San Diego, CA) and major histocompatibility complex (MHC) class II antigen expression using OX-6 anti H-2A class II antibody (Serotec). Immunostaining was visualized with Alexa-conjugated secondary anti-mouse and anti-rat antibodies (Molecular Probes, Eugene, OR). Negative controls for MHC class II detection were performed, and immunostaining was absent in microglial cells.

Determination of reactive microglial cell number. To determine the number of microglia with reactive morphology, five randomly selected ventral spinal cord images per mouse at different levels were obtained by confocal microscopy, with constant laser beam intensity and photodetector sensitivity. Images were analyzed with NIH Image software fixed to

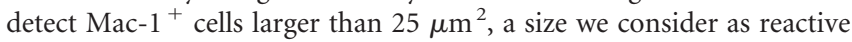
microglia. To confirm that this was a correct size threshold, we analyzed spinal cords from sham mice, and the software detected no cells in spinal cord, in which all microglial cells were resting. Moreover, reactive microglia detected by this method showed the same labeling intensity in vehicle-treated compared with cannabinoid-treated mice. Data were analyzed with one-way ANOVA followed by Tukey's multiple comparison test.

Determination of $\mathrm{CD} 4^{+}$. To determine $\mathrm{CD} 4^{+}$cell number, we counted positive cells in four random microscopic fields using a $40 \times$ objective. Five coronal sections were quantified per mouse at different spinal cord levels. The four fields counted per section were always two from the ventral and two from the dorsal region; two fields were from one hemisphere and two from the other. We performed one-way ANOVA followed by Tukey's multiple comparison test with data obtained.

Quantitation of spinal cord demyelination. Toluidine blue-stained semithin cross sections ( $1-\mu \mathrm{m}$-thick) of cervical, thoracic, and lumbar spinal cord were used for quantification. We counted both remyelinating fibers (a thin myelin sheath compared with normally myelinated axon fibers) and demyelinated axons (naked axons devoid of myelin) using a $100 \times$ objective. Counts were made in random fields within affected demyelinating areas in lateral, anterolateral, and anterior columns (the effect was minimal in the posterior column). We analyzed six animals per treatment, five sections per mouse, and five fields per area in each hemisphere. To determine statistical differences, we performed one-way ANOVA and Tukey's post-test.

\section{Results}

\section{Cannabinoid agonist treatment improves motor function on established neurological symptomatology}

Several studies correlate poor ability to perform rotarod test with demyelination induced by TMEV infection (McGavern et al., 1999). TMEV-infected mice exhibited reduced ability in rotarod performance before cannabinoid treatment compared with sham mice (Fig. 1). A two-way ANOVA revealed a significant effect of treatment $(p<0.001)$, time $(p<0.001)$, and treatment $\times$ time interaction $(p<0.001)$. To evaluate the effect of cannabinoids compared with the pretreatment situation, we performed Student's $t$ test within each cannabinoid-treated group. One day after a $10 \mathrm{~d}$ treatment protocol with the $\mathrm{CB}_{1} / \mathrm{CB}_{2}$ nonselective cannabinoid agonist WIN 55,212-2, mice showed increased ability to perform the test correctly $(p<0.001)$; this effect was also observed $25 \mathrm{~d}$ after cessation of treatment $(p<0.001)$. The selective $\mathrm{CB}_{1}$ agonist ACEA also increased the ability of TMEVinfected mice to perform the rotarod assay $1 \mathrm{~d}$ after the end of the treatment $(p<0.01)$ as well as at $25 \mathrm{~d}(p<0.01)$. The $\mathrm{CB}_{2}$ 


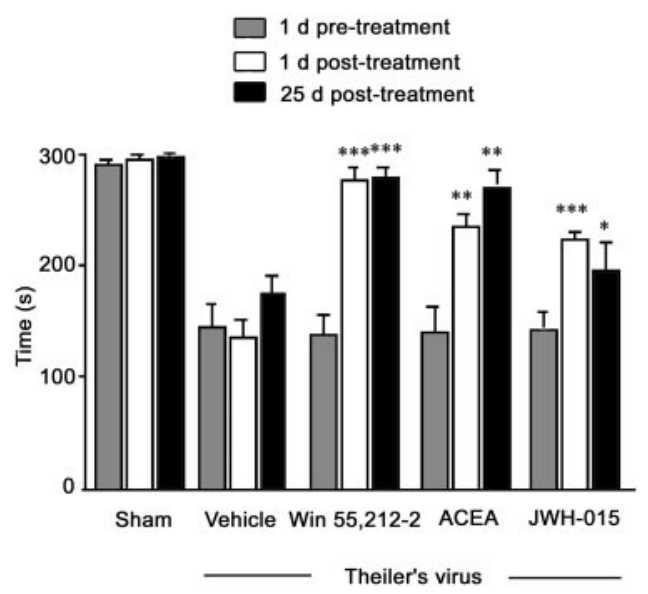

Figure 1. Cannabinoids induce long-term improvement of motor function. Data from the rotarod assay show a significant increase in motor function of WIN 55,212-2-treated (dose schedule: $2.5 \mathrm{mg} / \mathrm{kg}$ for $3 \mathrm{~d}, 3.75 \mathrm{mg} / \mathrm{kg}$ on days $4-6$, and $5 \mathrm{mg} / \mathrm{kg}$ on days $7-10$ ), ACEAtreated (dose schedule: $1.25 \mathrm{mg} / \mathrm{kg}$ on days $1-3,1.9 \mathrm{mg} / \mathrm{kg}$ on days $4-6$, and $2.5 \mathrm{mg} / \mathrm{kg}$ on the last $4 \mathrm{~d}$ of treatment), and JWH-015-treated (dose schedule: $0.6 \mathrm{mg} / \mathrm{kg}$ for $3 \mathrm{~d}, 0.9 \mathrm{mg} / \mathrm{kg}$ on days $4-6$, and $1.2 \mathrm{mg} / \mathrm{kg}$ on the last $4 \mathrm{~d}$ ) mice $1 \mathrm{~d}$ after the end of the $10 \mathrm{~d}$ treatment protocol, which is maintained for at least $25 \mathrm{~d}$ after cessation of treatment. ( ${ }^{* * *} p<0.001$ vs vehicle; ${ }^{* *} p<0.01$ vs vehicle; ${ }^{*} p<0.05$ vs vehicle).

selective agonist JWH-015, although it did not improve the motor ability of TMEV-infected mice to values similar to those of WIN 55,212-2 and ACEA, also improved rotarod performance at $1 \mathrm{~d}(p<0.001)$ and $25 \mathrm{~d}$ after treatment $(p<0.05)$. Thus, all cannabinoids used induce functional recovery of TMEV-infected
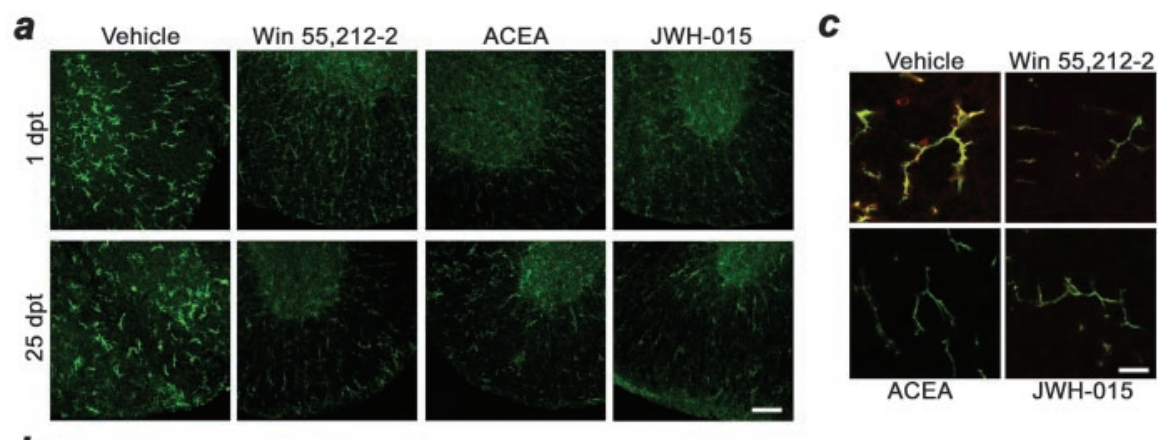

\section{b}

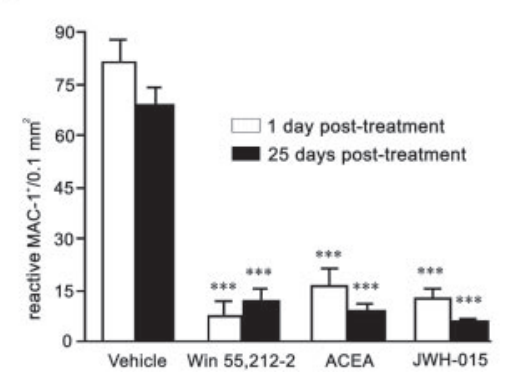

Figure 2. Cannabinoids inhibit microglial activation. $a$, Confocal images with constant laser beam and photodetector sensitivity of microglia/macrophages (CD11b ${ }^{+}$cells) in ventral spinal cord sections. Microglial cells in vehicle-treated mice show a reactive morphology at 1 and $25 \mathrm{~d}$ after treatment. In contrast, WIN 55,512-2, ACEA, and JWH-015 treatments markedly inhibit reactive morphology of microglia at 1 and $25 \mathrm{~d}$ after treatment. Scale bar, $50 \mu \mathrm{m}$. $b$, Treatment with cannabinoid agonists reduce the number of reactive microglial cells in the spinal cord at 1 and $25 \mathrm{~d}$ after treatment $\left(^{* * *} p<0.001\right.$ vs vehicle). c, Confocal images with constant laser beam and photodetector sensitivity of microglial MHC class II antigen expression. CD11b is shown in green, and the MHC class II complex is shown in red. Note antibody colocalization ( yellow) in vehicle-treated mice and the presence of cells other than microglia expressing MHC class II molecules. Cannabinoids abrogate microglial MHC class II expression. Images are representative of 1 and $25 \mathrm{~d}$ after $10 \mathrm{~d}$ cannabinoid treatment. Scale bar, $20 \mu \mathrm{m}$. treatment. mice that is maintained for at least $25 \mathrm{~d}$ after the termination of

\section{Cannabinoid agonists reduce microglial activation in TMEV-infected mice}

Microglial cells in the spinal cord of TMEV-infected mice showed a reactive morphology in white and gray matter; $10 \mathrm{~d}$ treatment with WIN 55,212-2, ACEA, or JWH-015 markedly switched their morphology toward a resting one (Fig. $2 a$ ). This effect was observed $1 \mathrm{~d}$ after treatment and was maintained for at least $25 \mathrm{~d}$ after treatment (Fig. 2a). Quantification of reactive microglia within the spinal cord and statistical analysis showed that the three cannabinoid agonists induced a significant reduction ( $p<0.001$ for all agonists) in the number of reactive microglial cells, both 1 and $25 \mathrm{~d}$ after the end of treatment (Fig. 2b).

Macrophage/microglial cells can process and present myelin epitopes, in association with MHC class II molecules, to $\mathrm{CD} 4{ }^{+} \mathrm{T}$ cells within the CNS of TMEV-infected mice (KatzLevy et al., 1999). Double immunostaining for Mac-1 and $\mathrm{H}-2 \mathrm{~A}$ (SJL/J MHC class II haplotype) revealed a predominant colocalization of MHC class II antigen expression on $\mathrm{Mac}-1^{+}$ cells in the white and gray matter of TMEV-infected mice spinal cords (Fig. 2c). One day after cannabinoid treatment, positive immunostaining for MHC class II almost disappeared in microglial cells with all three agonists. Importantly, this effect did not diminish by $25 \mathrm{~d}$ after the end of treatment (Fig. 2c).

\section{Cannabinoid treatment reduces the number of $\mathrm{CD}^{+}$} infiltrated $\mathrm{T}$ cells in the spinal cord of TMEV-infected mice TMEV-infected mice exhibited CD $4^{+}$infiltrated $\mathrm{T}$ cells within spinal cord white and gray matter (Fig. 3a). Cannabinoid treatment caused a significant reduction in the number of CD4 ${ }^{+} \mathrm{T}$ cells in the spinal cord $1 \mathrm{~d}$ after treatment $(p<0.05$ for WIN 55,212-2; $p<0.001$ for ACEA and JWH-015), as well as at $25 \mathrm{~d}$ after treatment $(p<0.05$ for WIN 55,212-2 and JWH-015; $p<0.01$ for ACEA) (Fig. $3 b$ ). Therefore, treatment of TMEVinfected mice with cannabinoids for $10 \mathrm{~d}$ reduced $\mathrm{CD} 4{ }^{+} \mathrm{T}$ cell infiltration in spinal cord for at least $25 \mathrm{~d}$ after treatment cessation.

\section{Cannabinoid agonists promote remyelination in TMEV-infected mice} Spinal cords of TMEV-infected mice showed disperse demyelination (Fig. 4a), preferentially distributed in anterior, anterolateral, and lateral columns. The number of axons affected (demyelinated plus remyelinated) in vehicle-treated and cannabinoid-treated mice was not significantly different, indicating that myelin lesions were similar in the different groups (data not shown). In spinal cords from cannabinoid-treated mice, however, there was a reduction in the number of demyelinated axons and a significant increase in the 
a

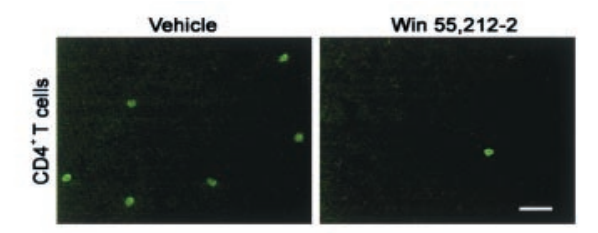

b

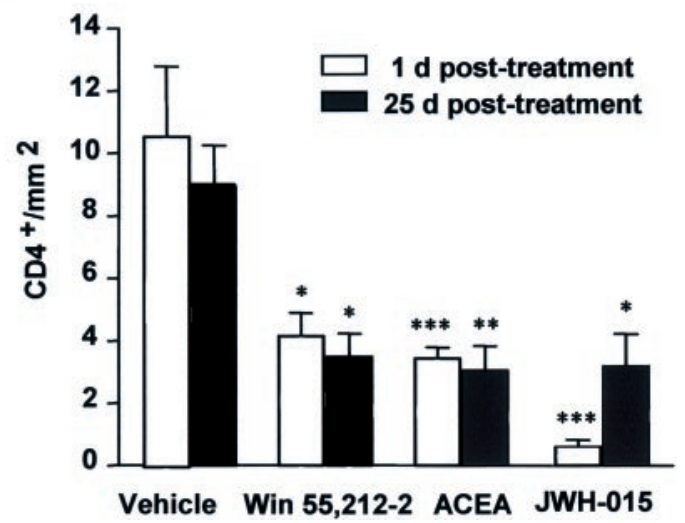

Figure 3. Cannabinoids reduce the number of $\mathrm{CD}_{4}{ }^{+}$-infiltrated T cells. $a$, Fluorescence microscopy images show $\mathrm{CD}^{+}{ }^{+} \mathrm{T}$ cells infiltrated in the spinal cord of TMEV-infected mice. Note the clear reduction in $\mathrm{CD} 4{ }^{+}$-infiltrated T cells in spinal cord from cannabinoid-treated mice. Scale bar, $8 \mu \mathrm{m}$. $b$, Cannabinoid agonist-treated mice show a reduction in the number of infiltrated $C D 4{ }^{+} T$ cells to less than half that of the vehicle-treated group at $1 \mathrm{~d}$ after treatment; this effect is maintained for $25 \mathrm{~d}\left({ }^{*} p<0.05\right.$ vs vehicle; ${ }^{* *} p<0.01$ vs vehicle; ${ }^{* * *} p<0.001$ vs vehicle).

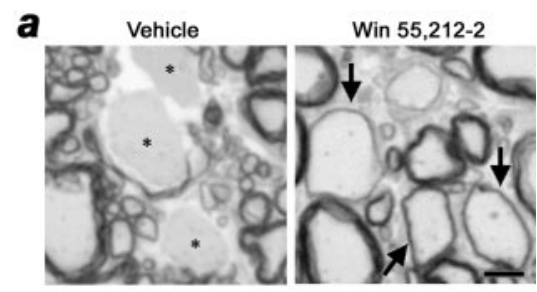

b

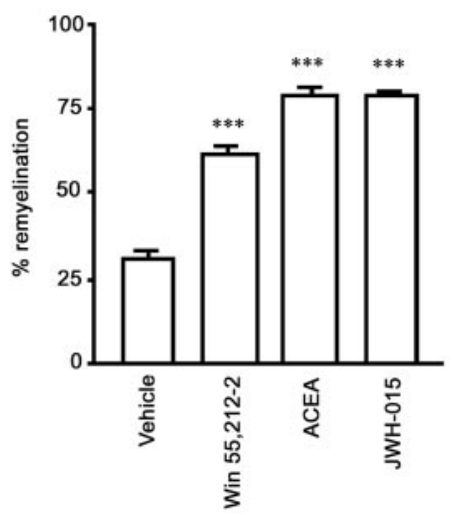

Figure 4. Cannabinoids promote spinal cord remyelination. $a$, Toluidine blue-stained semithin sections of spinal cord show demyelinated axons (asterisk) in a vehicle-treated mouse and thin compact myelin sheets in large axons, indicative of remyelination (arrows), in a WIN55,212-2-treated mouse. Scale bar, $5 \mu \mathrm{m}$. $b$, The percentage of remyelinated axons in cannabinoid-treated animals was more than twofold higher than in vehicle-treated mice ( ${ }^{* * *} p<0.001$ vs vehicle).

number of remyelinating axons $(p<0.001$ vs vehicle for the three agonists) (Fig. 4b). In fact, the percentage of remyelinating axons in cannabinoid-treated mice was more than twofold higher than in vehicle-treated mice.

\section{Discussion}

The present study reports that functional recovery of TMEVinfected mice induced by cannabinoid treatment parallels reduction in CNS inflammation and extensive remyelination.

As evaluated by rotarod performance, treatment with the cannabinoids, WIN 55,212-2, ACEA and JWH-015, improve motor coordination of TMEV-infected mice, suggesting the involvement of both $\mathrm{CB}$ receptors on such effect. However, because JWH-015 has also a low affinity for CB1 receptors, it cannot be excluded as a putative CB1-mediated effect. In the chronic relapsing EAE model of MS, Baker et al. (2000) found reductions on limb spasticity and tremor in mice treated with CB1 or CB2 selective agonists. Besides, the level of endocannabinoids increased in the spinal cord of diseased mice (Baker et al., 2001) and changes in the number of CB1 receptors occurred in motor pathways (Berrendero et al., 2001). Together, these observations suggest that endocannabinoids tonically control spasticity in animal models of MS. Therefore, a direct action of cannabinoids on the motor system may contribute to the amelioration observed in our study. However, the maintenance of recovery for at least $25 \mathrm{~d}$ after the end of treatment suggests that effects other than single modulation of motor pathways are involved.

Cannabinoids may promote long-lasting functional recovery by interfering with the inflammatory demyelinating process and by favoring myelin repair. All three agonists reduced the number of reactive microglia, almost suppressed microglial MHC class II antigen expression, and diminished CD4 ${ }^{+}$ $\mathrm{T}$ cell infiltration within the spinal cord of TMEV-infected mice. Therefore, cannabinoid treatment diminished components of the MHC class II-restricted $\mathrm{CD} 4{ }^{+} \mathrm{T}$ cell response. In addition, we show, to our knowledge for the first time, that cannabinoid treatment favors remyelination in the spinal cord of TMEV-infected mice. One possibility is that cannabinoids enhance myelin repair indirectly by inhibiting the immune response that contributes to demyelination or that hampers remyelination. Our results showing decreased number of $\mathrm{CD} 4^{+} \mathrm{T}$ cells in cannabinoid-treated mice support an immunomodulatory mechanism. In accordance with this, depletion of CD4 ${ }^{+}$T cells enhanced myelin repair (Fiette et al., 1993), and inhibition of the MHC class II-mediated response using anti-H-2A antibodies ameliorates TMEV-IDD (Friedmann et al., 1987). Further support derives from the observation that interferon- $\beta$, a cytokine used in MS treatment, inhibits MHC class II expression (Barna et al., 1989). Therefore, the reduction in the MHC class II-restricted CD4 ${ }^{+}$T cell response may be a key event leading to an increased capacity to remyelinate naked axons in cannabinoid-treated mice. Moreover, cannabinoids suppress the production of inflammatory molecules by astrocytes (F. Molina-Holgado et al., 1997, 2002) and microglial cells (Puffenbarger et al., 2000) perhaps, contributing to the effects observed in the present study.

The percentage of remyelinating axons in cannabinoidtreated mice reached values more than twofold higher than in vehicle-treated mice. In the progressive form of MS, the remyelination process remains abortive, and although multiple factors may be involved, the inflammatory environment has been considered a reliable candidate for such impediment (Noseworthy et al., 2000). The failure of remyelination in TMEV-IDD, which resembles progressive MS, may also be related to the inflammatory environment, because the decrease inflammation observed in cannabinoid-treated mice parallels an increase in remyelina- 
tion. The administration of high doses of $\Delta^{9}$-THC decreased clinical signs in EAE and also reduced CNS inflammation (Lyman et al., 1989). Recent observations indicate that remyelination progress more efficiently when is associated to the inflammatory process (for review, see Franklin, 2002). However, this occurs mainly in models of toxic demyelination in which the inflammatory response is a consequence of demyelination and not its cause, as occurs in immune-mediated demyelination. Under our experimental conditions, downregulation of the inflammatory response seems to establish a more favorable CNS environment for oligodendroglial cells to resume the myelination program. Oligodendroglial cells are damaged by inflammatory stimuli, whereas reduction of inflammation markedly rescues cell survival (Merril and Benveniste, 1996; Molina-Holgado et al., 2001). Thus, anti-inflammatory actions of cannabinoids may be important not only to restrain the demyelination process, but also to enhance the endogenous reparative remyelination. In addition, cannabinoids may favor myelin repair directly by acting on oligodendrocytes. Such hypothesis is supported by the expression of cannabinoid receptors in oligodendroglial cells and the protection of progenitors from apoptosis induced by deprivation of trophic support through a PI3K/Akt-dependent mechanism (E. Molina-Holgado et al., 2002). Therefore, we suggest that the effects of cannabinoids on remyelination result from both antiinflammatory actions and direct effects on oligodendrocyte survival and differentiation.

In conclusion, our data show a protective role of cannabinoids in experimental progressive, inflammatory demyelination. Such action of cannabinoids is probably exerted at several levels, as discussed above. The ability of cannabinoids to ameliorate established disease may have potential therapeutic implications in demyelinating pathologies such as MS, because treatment is started after the onset of clinical symptomatology. The involvement of CB2 receptors would enable nonpsychoactive therapy suitable for long-term use. Moreover, the pharmacological modulation of endocannabinoid system (Di Marzo et al., 2001) would be a future research target for the development of cannabinoid-based therapy in animal models of MS. Studies in progress are aimed to evaluate whether cannabinoids are actually involved in oligodendrocyte precursor recruitment and differentiation after demyelination.

\section{References}

Baker D, Pryce G, Croxford JL, Brown P, Pertwee RG, Huffman JW, Layward L (2000) Cannabinoids control spasticity and tremor in a multiple sclerosis model. Nature 404:84-87.

Baker D, Pryce G, Croxford JL, Brown P, Pertwee RG, Makriyannis A, Khanolkar A, Layward L, Fezza F, Bisogno T, Di Marzo V (2001) Endocannabinoids control spasticity in a multiple sclerosis model. FASEB J 15:300-302.

Barna BP, Chou SM, Jacobs B, Yen-Lieberman B, Ransohoff RM (1989) Interferon- $\beta$ impairs induction of HLA-DR antigen expression in cultured human astrocytes. J Neuroimmunol 23:45-53.

Berrendero F, Sanchez A, Cabranes A, Puerta C, Ramos JA, García-Merino A, Fernández Ruiz JJ (2001) Changes in cannabinoid CB1 receptors in striatal and cortical regions of rat with experimental allergic encephalomyelitis, an animal model of multiple sclerosis. Synapse 41:195-202.

Bouaboula M, Rinaldi M, Carayon P, Carillon C, Delpech B, Shire D, Le Fur G, Casellas P (1993) Cannabinoid-receptor expression in human leukocytes. Eur J Biochem 214:173-180.

Dal Canto MC, Lipton HL (1977) Multiple sclerosis-animal model: Theiler's virus infection in mice. Am J Pathol 88:497-500.

Devane WA, Hanus L, Breuer A, Pertwee RG, Stevenson LA, Griffin G, Gibson D, Mandelbaum A, Etingen A, Mechoulam R (1992) Isolation and structure of a brain constituent that binds to the cannabinoid receptor. Science 258:1946-1949.

Di Marzo V, Bifulco M, De Petrocellis L (2000) Endocannabinoids and multiple sclerosis: a blessing from the inner bliss? Trends Pharmacol Sci 21: 195-197.

Di Marzo V, Bisogno T, De Petrocellis L (2001) Anandamide: some like it hot. Trends Pharmacol Sci 22:346-349.

Fiette L, Aubert C, Brahic M, Peña Rossi C (1993) Theiler's virus infection of $\beta_{2}$-microglobulin-deficient mice. J Virol 67:589-592.

Franklin RJ (2002) Why does remyelination fail in multiple sclerosis? Nat Neurosci 3:705-714.

Friedmann A, Frankel G, Lorch Y, Steinman L (1987) Monoclonal anti-I-A antibody reverses chronic paralysis and demyelination in Theiler's virusinfected mice: critical importance of timing of treatment. J Virol 61:898-903.

Galiegue S, Mary S, Marchand J, Dussossoy D, Carriere D, Carayon P (1995) Expression of central and cannabinoid receptors in human immune tissues and leukocyte subpopulations. Eur J Biochem 232:54-61.

Herkenham M, Lynn AB, Little MD, Johson MR, Melvin LS, de Costa BR, Rice KC (1990) Cannabinoid receptor localization in brain. Proc Natl Acad Sci USA 87:1932-1936.

Johnson RT (1994) The virology of demyelinating diseases. Ann Neurol 36:54-60.

Katz-Levy Y, Neville KL, Girvin AM, Vanderlugt CL, Pope JG, Tan LJ, Miller SD (1999) Endogenous presentation of self myelin epitopes by CNSresident APCs in Theiler's virus-infected mice. J Clin Invest 104:599-610.

Klein TW, Lane B, Newton C, Friedman H (2000) Cannabinoid receptors and immunity. Proc Soc Exp Biol Med 225:1-8.

Lledó A, Borrell J, Guaza C (1999) Dexamethasone regulation of interleukin-1-receptors in the hippocampus of Theiler's virus-infected mice: effects on virus-mediated demyelination. Eur J Pharmacol 372:75-83.

Lyman WD, Sonett JR, Brosnan CF, Elkin R, Bornstein MB (1989) $\Delta^{9}$ tetrahydrocannabinol: a novel treatment for experimental autoimmune encephalomyelitis. J Neuroimmunol 23:73-81.

Malfait AM, Gallily R, Sumariwalla PF, Malik AS, Andreakos E, Mechoulam R, Feldmann M (2000) The nonpsychoactive cannabis constituent cannabidiol is an oral anti-arthritic therapeutic in murine collagen-induced arthritis. Proc Natl Acad Sci USA 97:9561-9566.

Matsuda LA, Lolait SJ, Brownstein MJ, Young AC, Bonner TI (1990) Structure of a cannabinoid receptor and functional expression of the cloned cDNA. Nature 346:561-564.

McCoy KL, Matmeyeva M, Carlisle SJ, Cabral GA (1999) Cannabinoid inhibition of the processing of intact lysozyme by macrophages: evidence for CB2 receptor participation. J Pharmacol Exp Ther 289:1620-1625.

McGavern DB, Zoecklein L, Drescher KM, Rodriguez M (1999) Quantitative assessment of neurologic deficits in a chronic progressive murine model of CNS demyelination. Exp Neurol 158:171-181.

McGavern DB, Murray PD, Rivera-Quiñones C, Schmelzer JD, Low PA, Rodriguez M (2000) Axonal loss results in spinal cord atrophy, electrophysiological abnormalities and neurological deficits following demyelination in a chronic inflammatory model of multiple sclerosis. Brain 123:519-531.

Mechoulam R, Ben Shabat S, Hanus L, Ligumsky M, Kaminski NE, Shatz AR, Gopher A, Almog S, Martin BR, Compton DR, Pertwee RG, Griffin G, Bayewitch M, Barg J, Vogel Z (1995) Identification of an endogenous 2-monoglyceride, present in canine gut, that binds to cannabinoid receptors. Biochem Pharmacol 50:83-90.

Merril JE, Benveniste EN (1996) Cytokines in inflammatory brain lesions: helpful and harmful. Trends Neurosci 19:331-338.

Miller SD, Vanderlugt CL, Begolka WS, Pao W, Yauch RL, Neville KL, KatzLevy Y, Carrizosa A, Kim BS (1997) Persistent infection with Theiler's virus leads to CNS autoimmunity via epitope spreading. Nat Med 3:1133-1136.

Molina-Holgado E, Vela JM, Arévalo-Martín A, Guaza C (2001) LPS/ IFN- $\gamma$ cytotoxicity in oligodendroglial cells: role of nitric oxide and protection by the anti-inflammatory cytokine IL-10. Eur J Neurosci 13:493-502.

Molina-Holgado E, Vela JM, Arévalo-Martín A, Molina-Holgado F, Almazán G, Borrell J, Guaza C (2002) Expression of cannabinoid CB1 receptors 
in oligodendroglial cells: activation of PI-3K/Akt signaling pathway promotes cell survival. J Neurosci 22:9742-9753.

Molina-Holgado F, Lledo A, Guaza C (1997) Anandamide suppresses nitric oxide and TNF- $\alpha$ responses to Theiler's virus or endotoxin in astrocytes NeuroReport 8:1929-1933.

Molina-Holgado F, Molina-Holgado E, Guaza C, Rothwell N (2002) Role of $\mathrm{CB} 1$ and $\mathrm{CB} 2$ receptors in the inhibitory effects of cannabinoids on lipopolysaccharide induced nitric oxide release in astrocyte cultures. J Neurosci Res 67:829-836.

Munro S, Thomas KL, Abu-Shaar M (1993) Molecular characterization of a peripheral receptor for cannabinoids. Nature 365:61-65.

Noseworthy JH, Lucchinetti C, Rodriguez M, Weinshenker BG (2000) Multiple sclerosis. N Engl J Med 343:938-952.

Pertwee RG (1999) Pharmacology of cannabinoid receptor ligands. Curr Med Chem 6:635-664.
Pertwee RG (2002) Cannabinoids and multiple sclerosis. Pharmacol Ther 95:165-174.

Piomelli D, Giuffrida A, Calignano A, Rodriguez de Fonseca F (2000) The endocannabinoid system as a target for therapeutic drugs. Trends Pharmacol Sci 21:218-224.

Puffenbarger RA, Boothe AC, Cabral GA (2000) Cannabinoids inhibit LPSinducible cytokine mRNA expression in rat microglial cells. Glia 29:58-69.

Warrington AE, Asakura K, Bieber AJ, Ciric B, Van Keulen V, Kaveri SV, Kyle RA, Pease LR, Rodríguez M (2000) Human monoclonal antibodies reactive to oligodendrocytes promote remyelination in a model of multiple sclerosis. Proc Natl Acad Sci USA 97:6820-6825.

Zhu W, Friedman H, Klein TW (1998) $\Delta^{9}$-Tetrahydrocannabinol induces apoptosis in macrophages and lymphocytes: involvement of bcl-2 and caspase-1. J Pharmacol Exp Ther 286:1103-1109. 